\title{
Research and Design of Reverse Logistics Network of Used Power Battery Based on Heuristic Algorithm
}

\author{
LongyuHe $\mathrm{H}^{1, *}$ \\ ${ }^{1}$ School of Economics, Wuhan University of Technology, Wuhan, China
}

\begin{abstract}
This pa per s tarts w ith the rapidity of ne w e nergy vehicles a nd the ha zards of po wer ba ttery disposal, and puts forward the importance of the construction of a reverse logistics network for used power batteries, and then analyzes the characteristics and operating modes of the reverse logistics network. Based on the results of the analysis, a heuristic is proposed. The algorithm uses a two-stage algorithm to solve the problem of $\mathrm{w}$ aste re verse logistics location-transportation, a nd proposes the de sign and construction of a reverse logistics network for waste power batteries, so that the recycling of waste power batteries can be better carried out.
\end{abstract}

\section{Introduction}

Power battery is an important component of new energy vehicles, and its performance parameters play a decisive role in the safety, cost, and cruising range of new energy vehicles. When the capacity of the power battery decays to $80 \%$, it will reach the vehicle scrap standard. With the rapid growth in the sales of ne w e nergy vehicles and their proportion in the overall a utomobile $\mathrm{m}$ arket, the power $b$ atteries it carries $w$ ill also $f$ ace large-scale scrapping. I $\mathrm{ft}$ he scrapped $\mathrm{p}$ ower $\mathrm{b}$ atteries cannot $\mathrm{b} e$ properly di sposed of, it $\mathrm{w}$ ill cause environmental pollution on the on e ha nd- For ex ample, the electrolyte in the power battery is mainly composed of carbonate a nd 1 ithium he xafluorophosphate. I $\mathrm{f}$ i 1 eaks accidentally, it $w$ ill $r$ eact $w$ ith $w$ ater $t o$ f orm a highly toxic hydrogen fluoride gas, posing a greater threat to the environment and safety; on the other hand, it will cause waste of resources. Power batteries contain a variety of valuable $m$ etals such as nickel, co balt, manganese, an d lithium. The mass production and use of power batteries has a $\mathrm{n}$ i mportant i mpact on the s upply a nd demand situation of my c ountry's c obalt a nd ni ckel $r$ esources. From the pe rspectives of e nvironment, resources a nd economy, it i s v ery necessary to recycle $\mathrm{s}$ crap power batteries of new energy vehicles.

\section{Reverse logistics network}

\subsection{Characteristics of reverse logistics network}

Reverse logistics is a part of the logistics activities of the entire supplyc hain. Reverse logistics and forward logistics a re c losely $r$ elated, $b$ ut $t$ here a re s till $\mathrm{m}$ any differences [1]. Compared $w$ ith $f$ orward $l$ ogistics, the characteristics of reverse logistics are as follows: (a) Reverse: Reverse logistics generally refers to the flow of recycled products from the downstream of the forward logistics to the upstream of the forward logistics, that is, the entire process from consumers to distributors, and from manufacturers to suppliers.

(b) U ncertainty: The scrap p roducts o f re verse logistics may involve any field and any department. The location, time and quantity of reverse logistics generally occur are difficult to determine.

(c) Slowness: When reverse logistics first a ppeared, the $\mathrm{n}$ umber $\mathrm{w}$ as ge nerally small, a nd o nly u nder the condition of continuous a ccumulation $\mathrm{c}$ an a larger flow pattern appear.

\subsection{The goal of reverse logistics}

In the process of reverse logistics operation, not only the improvement of economic efficiency is required, but also the $\mathrm{i}$ mpact of reverse 1 ogistics a ctivities on $\mathrm{t}$ he environment, society, an d resources. In the practice of recycling waste products, i t i s not o nly ne cessary t $o$ maximize the value of reuse and increase the recycling rate $\mathrm{o} f$ waste $\mathrm{p}$ roducts, $\mathrm{b}$ ut a lso to $\mathrm{m}$ inimize environmental pollution, a nd c arry o ut reverse logistics activities $\mathrm{t}$ hat ar $\mathrm{e}$ responsible $\mathrm{f}$ or $\mathrm{s}$ ociety an $\mathrm{dt}$ he environment. When the product is recycled, the goals of benefit, e nvironment, $\mathrm{s}$ ociety, a nd resources $\mathrm{c}$ an be organically combined.

Enterprises recycle w aste p roducts to i mprove their economic efficiency. If waste products, by-products and waste materials generated during the production process are di scarded, i t w ill not only c ause e nvironmental pollution, but a lso $\mathrm{c}$ ause $\mathrm{s}$ erious waste of $\mathrm{r}$ esources. Therefore, en terprises s hould $\mathrm{r}$ ecycle $\mathrm{w}$ aste pr oducts. Products, so as to achieve the goal of resource reuse and environmental $\mathrm{p}$ rotection, and $\mathrm{t}$ he $\mathrm{r}$ ecycled $\mathrm{w}$ aste products can $\mathrm{b}$ e r eprocessed and $\mathrm{m}$ anufactured, which 
can i mprove the ec onomic benefits of $t$ he en terprise. Therefore, $\mathrm{t}$ he $\mathrm{r}$ ecycling of $\mathrm{w}$ aste $\mathrm{p}$ roducts $\mathrm{w}$ ill inevitably become a $\mathrm{p}$ oint o fe conomic $\mathrm{g}$ rowth for enterprises[2].

\subsection{Operation mode of reverse logistics of waste power battery}

There are two main modes of reverse logistics operation for waste pow er batteries, on e is the op eration m ode jointly r esponsible for the consortium, and the o ther is the third-party recycling mode.

For the operation mode of joint responsibility, due to the small strength of individual enterprises, in the actual implementation process, $t$ hey $m$ ay e ncounter $t$ he situation that funds $c$ annot be returned in time and the recycling q uantity cannot meet $t$ he da ily needs of enterprises. It i s i $\mathrm{n} \mathrm{this} \mathrm{c}$ ontext $\mathrm{t}$ hat $\mathrm{t}$ he $\mathrm{c}$ onsortium operation model comes into be ing. The participants of this $\mathrm{m}$ odel ar e $\mathrm{p}$ ower battery $\mathrm{m}$ anufacturers, electric vehicle 1 easing c ompanies a nd el ectric vehicle $d$ ealers. The $t$ hree form a $\mathrm{s}$ trategic alliance an d e nter i nto a $\mathrm{n}$ agreement to establish a us ed battery recycling s ystem. When $\mathrm{t}$ here are used batteries $\mathrm{t}$ o b e r ecycled, $\mathrm{t}$ he members of $t$ he a lliance $w$ ill a ctively c ooperate $t \mathrm{o}$ complete $t$ he $r$ ecycling of us ed ba tteries. $T$ he $m$ ain features of $\mathrm{t}$ his model a re that it $\mathrm{c}$ an mobilize $\mathrm{v}$ arious members $\mathrm{i} n \mathrm{t}$ he $\mathrm{i}$ ndustrys ot hat hey have $\mathrm{t}$ he responsibility to cooperate with the recycling of power batteries; it has strong influence and wide coverage, and can achieve independent operation. The model is highly adaptable a nd can be a pplied $t \mathrm{o} b$ attery recycling i $n$ different $r$ egions of the c ountry. The flow $\mathrm{c}$ hart of the consortium's j ointly responsible o peration $\mathrm{m}$ odel i $\mathrm{s}$ shown in Figure 1.

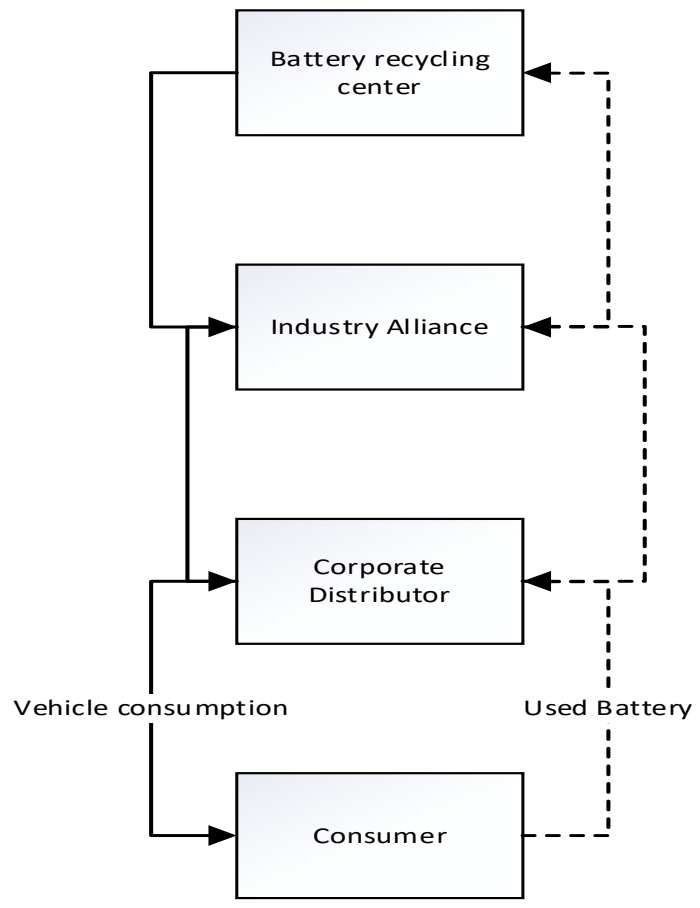

Figure 1 Flow chart of the consortium's jointly responsible operation
For the third-party recycling model, due to the scale and comprehensive strength of $\mathrm{p}$ ower battery manufacturers $\mathrm{v}$ ary, $\mathrm{s}$ ome manufacturers can $\mathrm{n}$ either build $\mathrm{t}$ heir own $\mathrm{r}$ ecycling $\mathrm{c}$ enters nor join $\mathrm{s}$ trategic alliances for their own reasons, so they c an e ntrust the recycling business t o t hird-party $r$ ecycling en terprises, which only need to pay a certain fee at that time. [3] In the $\mathrm{w}$ hole recycling pr ocess, the $\mathrm{r}$ ecycling of $\mathrm{u}$ sed batteries is carried out by the third party, which not only makes full us e of $\mathrm{s}$ ocial $\mathrm{r}$ esources for $\mathrm{c}$ omprehensive allocation, realizes eco nomy of s cale, but a lso s atisfies the recycling business of enterprises. The flow chart of the third-party recycling model is shown in Figure 2.

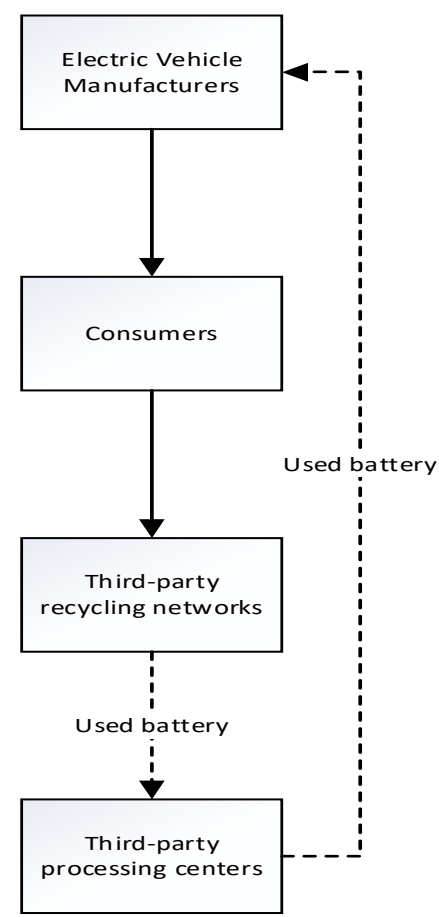

Figure 2 Flow chart of third-party recycling model

\section{Alorithm design reverse logistics network for used power batteries}

\subsection{Heuristic algorithm}

The 1 ocation a nd $t$ ransportation $\mathrm{p}$ roblem of $\mathrm{r}$ everse logistics network is a typical NP-hard problem, and the model solving time is generally long because the network has a 1 arge number of facility n odes. M odern heuristics a re $\mathrm{m}$ ainly used $\mathrm{f}$ or $\mathrm{t}$ he $\mathrm{s}$ olution of $\mathrm{s}$ uch problems. M odern he uristic algorithms are $\mathrm{m}$ ainly divided into the following categories.

One i s t he a nt c olony a lgorithm. T he ant c olony algorithm is inspired by the law of biological activities in nature, which simulates the mechanism of ants passing messages in the process of foraging or returning to the nest. A nts leave phe romones o $\mathrm{n}$ the $\mathrm{r}$ oute du ring crawling, an $\mathrm{dt}$ he pheromones a re $\mathrm{t}$ he medium for passing messages among ants. The higher the number of ants passing by, the higher the pheromone concentration on the route. Conversely, if the number of ants passing by is low, the pheromone concentration is lower, and the 
pheromone will be sent over time, and as time progresses, more a nd $\mathrm{m}$ ore a nts wi $11 \mathrm{c}$ hoose $\mathrm{t}$ he path with $\mathrm{m}$ ore pheromones to walk, and then find the shortest path. The main pa rameters of $t$ he a nt $c$ olony a lgorithm a re $t$ he probability selection function of the ants to carry out the state transfer i.e. to select the n ext visited node and the volatile coefficient of pheromone[4].

\subsection{Overview of Ant Colony Algorithm}

The a nt c olony algorithm, on the ot her ha nd, b orrows from $t$ he foraging be havior i $n$ na ture. $L$ et $m$ a nts a re placed in $n$ random regions, $C$ is the set of regions, $\tau_{-}$ij $(t)$ denotes the a mount $\mathrm{o}$ i nformation on $\mathrm{t}$ he paths of communities $i$ and $j$ at moment $t$, and $\eta$ ij is a heuristic factor that denotes the expected distance ants move from community $\mathrm{i}$ to community $\mathrm{j}$ at moment $\mathrm{t}$. Usually, $\eta$ ij is $t$ aken $a s$ the $\mathrm{i}$ nverse of $\mathrm{t}$ he distance $\mathrm{b}$ etween communities.

State $\mathrm{t}$ ransfer $\mathrm{p}$ robability c riterion. Each a nt independently s elects the next $r$ egion to be $t$ ransferred based on the amount of pheromone on e ach path, and records the regions traveled by ant $\mathrm{k}$ in the tabu_k of the taboo $t$ able. The s tate $t$ ransfer $p$ robability $p_{-} i j^{\wedge} k(t)$ of ant $\mathrm{k} \mathrm{m}$ oving from region $\mathrm{i}$ to region $\mathrm{j}$ at $\mathrm{moment} \mathrm{t}$ is shown in equation (1).

$$
p_{i j}^{k}(t)=\left\{\begin{array}{c}
\text { allowed }_{k}=\left\{C-\text { tabu }_{k}\right\} \\
\frac{\left[r_{i j}(t)\right]^{a} g\left[\eta_{i j}(t)\right]^{\beta}}{\sum_{s \in \text { allowsd, }_{,}\left[r_{i s}(t)\right]^{a} g\left[\eta_{i s}(t)\right]^{\beta}}}, \text { if } j \in \text { allowed }_{k} \\
0
\end{array}\right.
$$

In the formula, a is the information heuristic factor, reflecting the influence of pheromone on the an t's path selection, $\beta$ is the expectation heuristic factor, indicating the $\mathrm{i}$ nfluence of path $\mathrm{l}$ ength o $\mathrm{nt}$ he a $\mathrm{nt}$, a nd [ "allowed" \_k i s t he s et of regions t hat $\mathrm{c}$ an be selected by ant $\mathrm{k}$ when it moves next.

Pheromone update. After all an ts have co mpleted a traversal, $t$ he pheromones $r$ emaining on $t$ he paths a re updated, and the pheromones on each path are adjusted according to equation (2).

$$
\left\{\begin{array}{c}
\tau_{i j}(t+n)=(1-\rho) \cdot \tau_{i j}(t)+\Delta \tau_{i j}(t) \\
\Delta \tau_{i j}(t)=\sum_{k=1}^{m} \Delta \tau_{i j}^{k}(t)
\end{array}\right.
$$

where $\rho$ is the volatility coefficient, which reflects the persistence of pheromone, $\rho$ takes values between 0 and $1, \Delta \tau$ ij $(\mathrm{t})$ denotes the increment of pheromone on path $(\mathrm{i}, \mathrm{j})$ after this cycle, and $\Delta \tau_{-} \mathrm{ij}^{\wedge} \mathrm{k}(\mathrm{t})$ denotes the amount of pheromone left by the kth ant on path (i,j).

$$
\Delta \tau_{i j}^{k}(t)=\left\{\begin{array}{c}
\frac{\underline{Q}}{L_{k}}, \text { if the } k \text { th ant passes }(i, j) \text { in this cycle } \\
0, \text { others }
\end{array}\right.
$$

In $\mathrm{t}$ he formula, $\mathrm{L} \_\mathrm{k}$ i s t he $\mathrm{s}$ um of $\mathrm{t}$ he di stance traveled by the $\mathrm{k}$ th ant in this cycle, and $\mathrm{Q}$ is the total amount of pheromones $r$ eleased $b$ y $t$ he an ts af ter completing a path search. The model updates the pheromones on the path using the information of all the ants after completing the cycle. The flow chart of the ant colony algorithm is shown in Figure 3.

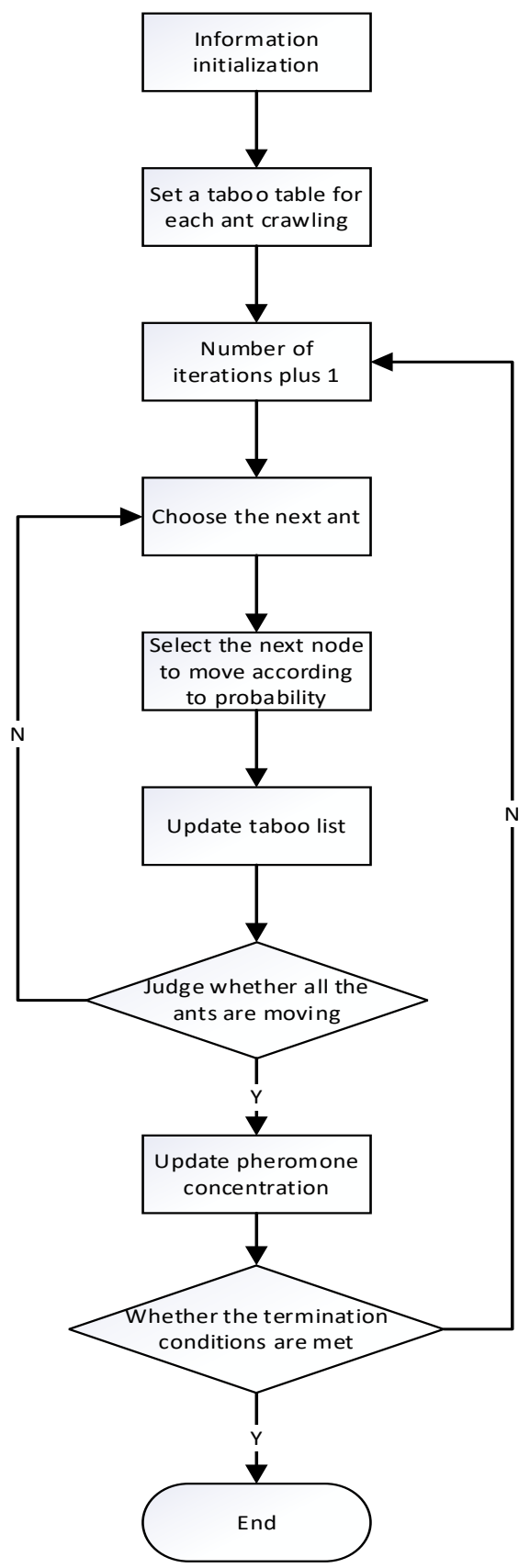

Figure 3 Flow chart of ant colony algorithm

\subsection{Collection vehicle path optimization and scheduling problem solution}

In $\mathrm{t}$ he $\mathrm{f}$ irst stage, the waste collection points a re classified by c luster a nalysis a nd $\mathrm{i}$ ncluded $\mathrm{i} n \mathrm{t}$ he corresponding transfer stations. In addition to the relative coordinate positions of $t$ he $c$ ollection $p$ oints a nd $t$ he transfer $\mathrm{s}$ tations, $\mathrm{t}$ he c lustering process should a lso include $t$ he $\mathrm{c}$ apacity 1 imitation of $\mathrm{t}$ he $\mathrm{t}$ ransfer $\mathrm{s}$ tations and the incremental di stance of the collection vehicles due to the collection frequency of the collection points. In this stage, the reasonable service area of each transfer station i s d etermined, a nd t he $\mathrm{t}$ ransfer stations with excess $t$ ransfer cap acity ar e cl osed $o n$ the $b$ asis of meeting the service demand of each collection point to achieve $t$ he purpose of $r$ educing $t$ he $t$ otal $c$ ost of $t$ he 
reverse l ogistics n etwork; o $r$ the $t$ ransfer stations w ith insufficient capacity a re dynamically a djusted $f$ or $t$ he collection $\mathrm{p}$ oints, a nd $\mathrm{t}$ he $\mathrm{o}$ ptimal $\mathrm{c}$ ombination o $\mathrm{f}$ transfer $\mathrm{s}$ tations a nd $\mathrm{t}$ he $\mathrm{s}$ ervice a rea $\mathrm{r}$ ange of each transfer station in the study area are finally determined.

The second stage solves the driving path of collection vehicles i $\mathrm{n} t$ he $\mathrm{s}$ ervice a rea o f eac $\mathrm{h} \mathrm{t}$ ransfer s tation obtained in the first stage by ant colony algorithm. Since the collection $\mathrm{p}$ oints $\mathrm{h}$ ave $\mathrm{d}$ ifferent collection frequencies, the driving path of the collection vehicles in the $s$ ervice ar ea o $\mathrm{f} e$ ach $\mathrm{t}$ ransfer $\mathrm{s}$ tation $\mathrm{n}$ eeds $\mathrm{t} o$ be designed for two days. The driving path of the first day visits a ll the collection p oints that a re collected once a day and some of the collection points that are collected once every other day, while the collection route of the second day visits the collection points that are collected once a day and the remaining collection points that are collected every other day. The travel path is determined to meet the overall minimum cost of the two-day travel path and $\mathrm{t} o$ meet $\mathrm{t}$ he $\mathrm{c}$ onstraints of $\mathrm{t}$ he $\mathrm{m}$ aximum capacity $l$ imit o $\mathrm{ft}$ he $\mathrm{t}$ ransfer station, $\mathrm{t}$ he $\mathrm{m}$ aximum loading capacity of the collection vehicle and the operating time limit [5].

After the second stage is completed, the combination strategy of transfer stations can be changed and adjusted to $r$ e-enter the s olution a gain a nd $r$ epeat the $t$ wo-stage solution process. The two-stage a lgorithm design of the LRP problem is shown in Figure 4.

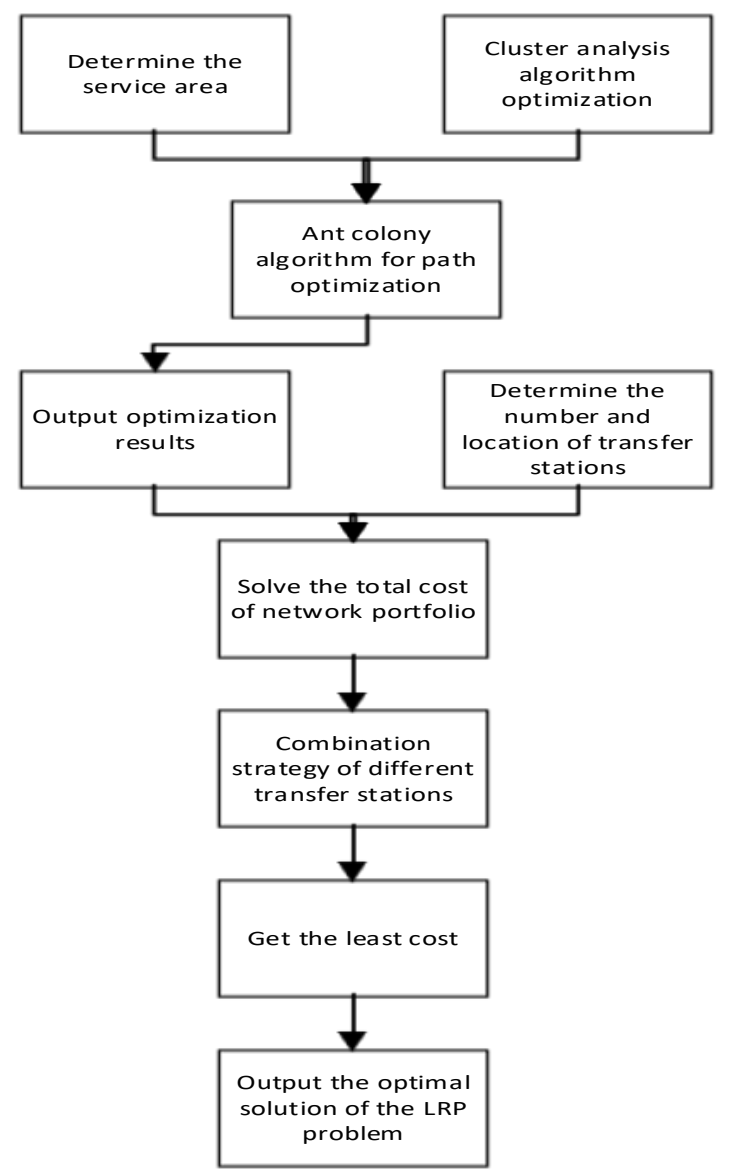

Figure 4 Two-stage algorithm design for LRP problem

\section{Conclusion}

In recent years, with the agravation of w aste pollution problem and the enhancement of people's awareness of environmental pr otection, $t$ he $r$ esearch i $n$ the $f$ ield of reverse $\mathrm{w}$ aste logistics $\mathrm{h}$ as received $\mathrm{m}$ ore an $\mathrm{dm}$ ore attention. $T$ his $p$ aper $s$ ummarizes an $d r$ esearches $t$ he theories of $\mathrm{w}$ aste a nd $\mathrm{i}$ ts $\mathrm{r}$ everse 1 ogistics $\mathrm{n}$ etwork $\mathrm{b} \mathrm{y}$ combining $t$ he $r$ elevant research $t$ heories o f $r$ everse logistics at home and abroad, c onstructs the LRP mathematical model of waste reverse logistics network, adopts the two-stage heuristic a lgorithm combining the least envelope cluster analysis and ant colony algorithm to optimize the combination of transfer s tations and the driving route arrangement of collection vehicles in the collection cycle.Through the design of the reverse logistics network of us ed power batteries, the recycling of used power batteries can be better carried out.

With th e c ontinuous pr omotion of $\mathrm{n}$ ew e nergy vehicles, $\mathrm{t}$ he $\mathrm{s}$ cale o f $\mathrm{p}$ ower battery application i $\mathrm{s}$ gradually expanding, and the accompanying problem of battery replacement a nd e limination is becoming $m$ ore and $\mathrm{m}$ ore $\mathrm{p}$ rominent. $\mathrm{T}$ he purpose of power battery recycling $\mathrm{i} \mathrm{st}$ o av oid waste of resources a nd environmental $\mathrm{p}$ ollution, $\mathrm{t}$ herefore, $\mathrm{i} t \mathrm{i}$ s necessary $\mathrm{t} \mathrm{o}$ establish a $r$ everse 1 ogistics ne twork f or waste $p$ ower battery $r$ ecycling, and the $s$ tudy of $r$ everse logistics network for waste power battery can lay the theoretical foundation $\mathrm{f}$ or $\mathrm{t}$ he e stablishment of reverse 1 ogistics network.

\section{References}

1. Wu Di. Research on vehicle path optimization based on genetic a nt c olony hybrid a lgorithm [D]. Hebei Engineering University,2020.

2. Gan J W, Luo L, Kou R . Research pr ogress a nd trends i $\mathrm{n} \mathrm{s}$ ustainable $\mathrm{r}$ everse 1 ogistics $\mathrm{n}$ etwork design[J].C ontrol a nd D ecision Making,2020,35(11):2561-2577.

3. Geng LY, Zhang N, Zhang ZF. Planning and design of r everse logistics n etwork for recycling lead-acid batteries $\mathrm{f}$ or e lectric bicycles[J]. Logistics Technology, 2020, 39(08): 8-11.

4. Liu T. Research on improvement and application of ant c olony o ptimization a lgorithm[D]. In ner Mongolia University for Nationalities,2020.

5. Jiang Lina. Re search a nd Application A nalysis of Packaging W aste Recycling Based on Reverse Logistics N etwork[D]. Xi'an U niversity o f Technology, 2020. 